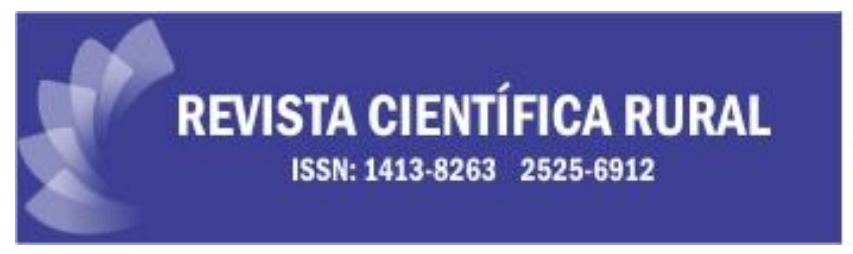
Técnico-Científica

\title{
USO DE ADITIVOS ALIMENTARES PARA PEIXES ORNAMENTAIS
}

\author{
Veruska Dilyanne Silva Gomes ${ }^{1 *}$, Cácio Ribeiro Cavalcanti², João Marcos Monteiro Batista ${ }^{3}$, \\ Francisco Glauco de Araújo Santos ${ }^{4}$, José Jordão Filho ${ }^{5}$

\footnotetext{
${ }^{1}$ Professora Doutora. Instituto Federal de Educação, Ciência e Tecnologia do Tocantins, campus Dianópolis (IFTO). *email: veruska_sgomes@yahoo.com.br;

2 Doutorando em Engenharia Agrícola, Universidade Federal de Campina Grande (UFCG);

${ }^{3}$ Doutorando em Zootecnia, Universidade Federal do Goiás (UFG).

${ }^{4}$ Professor Doutor. Universidade Federal do Acre (UFAC).

${ }^{5}$ Professor Doutor. Universidade Federal da Paraíba (UFPB).
}

\begin{abstract}
RESUMO: Aditivos alimentares adicionados às rações têm demonstrado resultados positivos na piscicultura ornamentais. No entanto, estudos relacionados à sua adição para espécies ornamentais ainda são escassos, principalmente, em um segmento onde a variedade de espécies é uma característica marcante. A utilização de aditivos alimentares pode favorecer a qualidade das rações e seus efeitos sobre o desempenho dos animais. Nesse âmbito, a presente revisão foi elaborada com o objetivo de apresentar informações sobre a utilização de enzimas, pigmentos, prebióticos, probióticos e simbióticos em dietas para peixes ornamentais. As enzimas digestivas promovem melhor aproveitamento dos nutrientes da dieta, refletindo na melhoria dos índices de desempenho. Os pigmentos atuam intensificando a coloração dos exemplares, aumentando seu valor comercial, e promovem efeito positivo sobre crescimento, desenvolvimento e resposta imune, assim como os aditivos prebióticos, probióticos e simbióticos.
\end{abstract}

Palavras-chave: Pigmentos, probióticos, prebióticos, simbióticos, enzimas exógenas.

\section{USE OF FOOD ADDITIVES FOR ORNAMENTAL FISH}

ABSTRACT: Food additives added to diets have shown positive results in ornamental fish farming. However, studies related to its addition to ornamental species are still scarce, especially in a segment where the variety of species is a striking feature. The use of food additives can favor the quality of the feed and its effects on the performance of the animals. In this context, the present review was prepared with the objective of presenting information on the use of enzymes, pigments, prebiotics, probiotics and symbiotics in diets for ornamental fish. Digestive enzymes promote better use of nutrients in the diet, reflecting in the improvement of 
performance indexes. The pigments act by intensifying the color of the specimens, increasing their commercial value, and promoting a positive effect on growth, development and immune response, as well as prebiotic, probiotic and symbiotic additives.

Keywords: Pigments, probiotics, prebiotics, sibiotics, exogenous enzymes

\section{INTRODUÇÃO}

A piscicultura ornamental é um segmento em constante crescimento, aspecto que está fortemente relacionado ao aumento da demanda pelo consumidor final e ao alto lucro com a comercialização de espécies nativas e exóticas (GOMES et al., 2019). Obtendo um faturamento mundial superior a 15 milhões de dólares, onde mais de 2 bilhões de espécies ornamentais são comercializadas (VASANTHAKUMARAN et al., 2020). Nesse ambito, se torna imprescindível que a produção de rações atenda em quantidade e qualidade tanto o piscicultor comercial quanto o aquariofilista.

A alimentação pode representar altos custos de produção na piscicultura ornamental, havendo a necessidade de buscar inovações que possibilitem melhorar o desempenho zootécnico, resistência a doenças, aumento da resposta imune e diminuição da mortalidade dos peixes (FIROUZBAKHSH et al., 2011).

Entre as inovações no setor da nutrição de peixes ornamentais estão os aditivos alimentares, como as enzimas exógenas (GOMES et al., 2018), prebióticos (ABASALI e MOHAMAD, 2011), probióticos (FIROUZBAKHSH et al., 2011) e simbióticos (AZEVEDO et al., 2016), que tem demostrado resultados positivos sobre o desempenho e imunidade dos peixes.

Outros aditivos utilizados na fabricação de rações para peixes ornamentais são os pigmentos, que tem como função base a intensificar da coloração da pele. Um dos principais pigmentos utilizados são os carotenoides, que também contribuem para o aumento da resposta imunológica e melhora o desempenho dos peixes (ZUANO et al., 2011; FRIES et al., 2014). 
Estudos relacionados à utilização de aditivos alimentares para espécies ornamentais ainda são escassos, mas podem contribuir para a fabricação de rações que, além de atender as exigências nutricionais das espécies, contribuam para o aumento da digestibilidade dos ingredientes, o fortalecimento da imunidade e a intensificação da coloração dos indivíduos, fator preponderante para a escolha dos exemplares. Nesse âmbito, a presente revisão foi elaborada com o objetivo de apresentar informações sobre a utilização de enzimas, pigmentos, prebióticos, probióticos e simbióticos em dietas para peixes ornamentais.

\section{ENZIMAS DIGESTIVAS}

As enzimas são catalizadores de reações metabólicas indispensáveis para a sobrevivência dos seres vivos. São proteínas, em sua maioria, que atuam em substrato especifico, por meio de sítio ativo, aumentando a velocidade das reações sem alterar o equilíbrio químico. Também apresentam especificidade em relação às condições de $\mathrm{pH}$ e temperatura do meio (NELSON e COX, 2014).

Os peixes produzem diversas enzimas digestivas responsáveis pelo processo de digestão de nutrientes no lúmen do intestino, como a lipase que atua na degradação de lipídeos e as proteases que hidrolisa as ligações peptídicas das proteínas, disponibilizando aminoácidos para absorção pelo organismo (SAKOMURA et al., 2014).

O perfil e atividade das enzimas digestivas de produção endógena podem variar de acordo com o hábito alimentar do peixe ornamental ou a presença de alimento do trato digestivo. Em experimento realizado com o peixe betta (espécie carnívoro) e o kinguio (espécie onívoro) avaliando a atividade das enzimas protease, lipase e amilase, foi observado aumento da atividade das três enzimas nos bettas alimentados com ração e diminuição da atividade da lipase nos exemplares mantidos em jejum (DORCE et al., 2020).

Para os peixes kinguios foi observado aumento da atividade da lipase e amilase, porém, não houve diferença entre a atividade da protease em animais alimentados ou mantidos em jejum. Deste modo, é possível observar que o aumento 
da atividade de algumas enzimas digestivas endógenas pode ser modulado pela alimentação (DORCE et al., 2020), no entanto, para aumentar a eficiencia da digestão outras necessitariam de suplementação exógena.

Nesse âmbito, as enzimas digestivas de produção exógena podem ser adicionadas nas rações para peixes com a finalidade de complementar a atividade enzimática do organismo, quando já existe produção endógena da enzima (como a protease, lipase e tripsina); ou de suprir a necessidade de enzimas que não são sintetizadas pelos peixes, mas que são necessárias para degradar um determinado nutriente presente nas rações, como as enzimas fitase e celulase (GOMES et al., 2016).

As enzimas digestivas destinadas à alimentação animal podem ser de origem vegetal, animal, de leveduras, bactérias ou fungos (CAMPESTRINI et al., 2005). Nas rações para peixes podem ser adicionadas de forma unitária, como complexos (quando todas as enzimas presentes na mistura tem uma mesma origem) ou como misturas denominadas coquetéis ou "blends" (quando as enzimas incorporadas possuem origens distintas) (GOMES et al., 2016).

Estudos direcionados a inclusão de enzimas na alimentação de peixes ornamentais são escassos, no entanto, esses aditivos têm demonstrado efeitos positivos quando adicionados à dieta de kinguios (Carassius auratus), pangasius (Pangasianodon hypophthalmus), bettas (Betta splendens) e guppy (Poecilia reticulata).

A adição de enzimas digestivas em dietas para espécies ornamentais pode promover resultados promissores, como os observados nas espécies de corte. Nesse âmbito, a adição de $1,5 \mathrm{~g} / \mathrm{kg}$ de celulase, enzima não produzida de forma endógena por peixes, na dieta do peixe ornamental kinguio (Carassius auratus) promoveu um melhor aproveitamento dos nutrientes da dieta, refletindo na melhoria dos índices de desempenho (SHI et al., 2017).

Para o pangasius (Pangasianodon hypophthalmus), espécie destinada tanto para corte quanto para a piscicultura ornamental, a adição da enzima alfa-amilase 
na proporção de 500 ppm na dieta, melhorou o ganho de peso, a taxa de crescimento específico e a conversão alimentar dos peixes (KHALIL et al., 2018).

A utilização de misturas ou complexos enzimáticos pode trazer benefícios por permitir que diversas enzimas atuem de forma conjunta. Para a espécie ornamental carnívora betta (Betta splendens) na fase juvenil, a adição de protease e alfaamilase de forma unitária ou conjunta em uma dieta comercial, melhorou o crescimento final dos peixes alimentados com as dietas contendo protease $(100 \mathrm{ppm})$, alfa-amilase $(100 \mathrm{ppm})+$ protease $(200 \mathrm{ppm})$ e alfa-amilase $(200 \mathrm{ppm})+$ protease (400 ppm) (GOMES et al., 2018).

O "blend" composto pelas enzimas alfa-amilase, protease e fitase em dietas para o peixe ornamental onívoro guppy (Poecilia reticulata) na fase juvenil promoveu maior peso final, ganho em peso, altura final e melhor conversão alimentar quando comparado aos animais que receberam ração sem enzimas exógenas (GOMES et al., 2017). As taxas de crescimento específico e desenvolvimento específico também foram mais altas nos peixes que receberam a ração contento enzimas digestivas (Tabela 1).

Tabela 1 - Taxas de crescimento e desenvolvimento específicos de guppys alimentados com ração contendo ou não enzimas exógenas.

\begin{tabular}{lcc}
\hline & $\begin{array}{r}\text { Taxa de crescimento } \\
\text { específico }(\% / \text { dia })\end{array}$ & $\begin{array}{c}\text { Taxa de desenvolvimento } \\
\text { específico } \% / \text { dia })\end{array}$ \\
\hline Dieta controle (DC) & $6,22^{\mathrm{b}}$ & $1,74^{\mathrm{b}}$ \\
DC + Enzimas & $7,20^{\mathrm{a}}$ & $2,20^{\mathrm{a}}$ \\
\hline CV\% & 3,81 & 10,73
\end{tabular}

*Médias na mesma coluna seguidas de letras distintas diferem $(\mathrm{P}<0,05)$ pelo teste t. (Adaptado de Gomes et al., 2017).

\section{PIGMENTOS}

Em ambientes naturais, os peixes ornamentais consomem alimentos ricos em pigmentos, o que propicia coloração intensa. No entanto, não são capazes de sintetizar estes pigmentos de forma endógena, havendo a necessidade de 
suplementação nas rações, visto que, a diminuição da coloração da pele diminui o valor comercial dos peixes ornamentais (ZUANO et al., 2011).

Alguns fatores além da concentração de pigmentos na dieta podem afetar a pigmentação dos peixes, como fatores genéticos, idade, maturação sexual, temperatura da água, tamanho e o período de suplementação (GOUVEIA e REMA, 2005).

As cores vermelhas e amarelas intensas dos peixes ornamentais são proporcionadas principalmente pelos carotenoides. Essas substâncias favorecem não só a intensificação da pigmentação dos peixes como também aumentam a resistência ao estresse, aumentam a resposta imunológica e favorecem o desempenho zootécnico (ZUANO et al., 2011; FRIES et al., 2014).

Sun et al. (2012), ao avaliarem a adição de pigmentos comerciais e naturais, entre eles a microalga Spirulina platensis, na dieta de carpas ornamentais Koi (Cyprinus carpio L.) observaram que houve intensificação da coloração dos animais alimentados com ração contendo $1,5 \mathrm{~g} / \mathrm{kg}$ do pigmento comercial vermelho e com a ração contendo $75,0 \mathrm{~g} / \mathrm{kg}$ de Spirulina, quando comparados aos peixes que receberam dieta controle. Portanto, aumentou o conteúdo de carotenoides nas escamas pretas e vermelhas e o conteúdo de xantofilas na pele das regiões pretas e vermelhas.

Fontes sintéticas de pigmentos possuem custo elevado quando comparadas as fontes naturais (SUN et al., 2012), por isso, estudos avaliando a utilização de fontes naturais como o urucum, spirulina, flores como a calêndula e frutas tem sido utilizadas com sucesso em espécies ornamentais (Tabela 2).

A adição entre 1,0 e 4,0\% de urucum, fonte natural de pigmentos como os carotenóides e flavonoides, em dietas para kinguios intensificou a coloração vermelho-amarela e melhorou variáveis de desempenho como o peso final, ganho em peso, conversão alimentar aparente, taxa de crescimento diário e eficiência alimentar (FRIES et al., 2014). 
Tabela 2 - Fontes naturais de pigmentos utilizadas na alimentação de peixes ornamentais.

\begin{tabular}{|c|c|c|c|c|}
\hline Espécie Ornamental & $\begin{array}{l}\text { Fonte } \\
\text { natural }\end{array}$ & $\begin{array}{l}\text { Concentração } \\
(\mathrm{g} / \mathrm{Kg})\end{array}$ & $\begin{array}{l}\text { Principais } \\
\text { pigmentantes }\end{array}$ & Referencia \\
\hline $\begin{array}{l}\text { Kinguio (Carassius } \\
\text { auratus) }\end{array}$ & Urucum & 10 a 40 & Bixina & Fries et al., 2014 \\
\hline $\begin{array}{l}\text { Carpa Koi (Cyprinus } \\
\text { carpio L.) }\end{array}$ & Spirulina & 75 & $\begin{array}{l}\text { Clorofila e } \\
\text { Bcaroteno }\end{array}$ & Sun et al., 2012 \\
\hline $\begin{array}{l}\text { Tricogáster ( } \\
\text { Trichogaster fasciata) }\end{array}$ & Mamão & 40 & $\begin{array}{l}\text { Licopeno, } \beta \text { - } \\
\text { criptoxantina e } \\
\text { ßcaroteno }\end{array}$ & $\begin{array}{l}\text { Das e Biswas, } \\
2020\end{array}$ \\
\hline $\begin{array}{l}\text { Tricogáster azul } \\
\text { (Trichogaster } \\
\text { trichopterus) }\end{array}$ & Calêndula & 24 & $\begin{array}{l}\text { Flavoxantina e } \\
\text { auroxantina }\end{array}$ & $\begin{array}{l}\text { Jorjani et al., } \\
2019\end{array}$ \\
\hline $\begin{array}{l}\text { Guppy (Poecilia } \\
\text { reticulata) }\end{array}$ & Açafrão & 45 a 50 & Curcumina & $\begin{array}{l}\text { Mukherjee et al. } \\
2009\end{array}$ \\
\hline
\end{tabular}

Fonte: Elaborado pelos autores.

Desta forma, a inclusão de ingredientes como fonte de pigmentos nas dietas para peixes ornamentais melhora não só a intensidade da coloração como também promove efeito positivo sobre crescimento, desenvolvimento e resposta imune de espécies ornamentais (MUKHERJEE et al. 2009; DAS e BISWAS, 2020).

\section{PREBIÓTICOS, PROBIÓTICOS, SIMBIÓTICOS}

Os aditivos alimentares prebióticos podem ser caracterizados como compostos não digeríveis pelo organismo animal, que são substrato seletivamente fermentado por bactérias intestinais benéficas, que auxilia na modulação da microflora intestinal do indivíduo ao beneficiar a proliferação de microrganismos benéficos em detrimento dos microrganismos patogênicos (DIONIZIO et al., 2002).

Os oligossacarídeos frutoligossacarídeos (FOS), glucoligossacarídeos e mananoligossacarideos (MOS) são os prebióticos mais utilizados na alimentação de não ruminantes (DIONIZIO et al., 2002). Pesquisas relacionadas à inclusão de prebióticos em dietas para peixes ornamentais são escassas, no entanto, os 
resultados têm demonstrado efeitos positivos sobre o crescimento e índices reprodutivos das espécies.

Larvas do peixe zebra (Danio rerio) alimentadas com dietas contendo $4 \mathrm{~g} / \mathrm{kg}$ de mananoligossacarideos (MOS) obtiveram melhores índices de crescimento e sobrevivência, além de demostrar reduzido comportamento relacionado ao estresse (FORSATKAR et al., 2017).

A utilização de prebióticos em dietas para reprodutores ornamentais podem refletir positivamente nos índices reprodutivos e na qualidade dos descendentes. Platys (Xiphophorus maculatus) alimentados com rações contendo prebióticos obtiveram maiores índices de produção de larvas, fecundidade e produziram larvas com maior comprimento (ABASALI e MOHAMAD, 2011).

O uso dos probióticos na aquicultura vem sendo estudado no intuito de substituição aos antibióticos, onde o principal objetivo é controle imediato da ocorrência de enfermidades, do meio aquático ao organismo animal, uma vez que o meio aquoso favorece a proliferação de microrganismos patógenos. Assim, os probióticos vem apresentado resultados satisfatórios de desempenho quando os animais encontram em desafio sanitário, mantendo a qualidade da microflora intestinal dos peixes. Ferreira et al. (2015), avaliaram a utilização de cepa probiótica Saccharomy cerevisiae, em dietas para pós-larvas de tilápias, sobre desafio sanitário (fezes de ovinos), observaram melhorias de desempenho, sobrevivência e índice hepatossomático para as pós-larvas que receberam $1 \mathrm{~g} \cdot \mathrm{kg}^{-1}$ de probiótico na ração equiparando aos peixes criados em água limpa.

Probióticos são organismos vivos, não digeríveis no intestino, quando incorporados aos alimentos competem com patógenos pelos mesmos sítios de adesão ou ligação no epitélio intestinal e pelo consumo de nutrientes, fazendo com que estes não se desenvolvam no trato gastrointestinal, aumentando a imunidade e a resistência a patógenos. São usados como reguladores da microbiota intestinal, imunomoduladores e promotores de crescimento. Vários microrganismos são 
comumente utilizados como probióticos, entre eles leveduras, bactérias ácidolácticas e bactérias não ácido lácticas (COPPOLA e TURNERS, 2004).

A utilização de cepas das bactérias Enterococcus faecium (concetração de $2 \times$ 106 UFC ml g - 1 na dieta) como probiótico adicionado as rações melhorou a resposta imune, o crescimento, ganho de peso, taxa de crescimento específico e conversão alimentar dos peixes acará-bandeira (Pterophyllum scalare) ao longo de um período de 40 dias (DIAS et al., 2019).

Peixes ornamentais Oscar (Astronotus ocellatus) alimentados com dietas contendo $0,15 \mathrm{~g} / \mathrm{kg}$ de probiótico (composto por sete espécies de bactérias, duas espécies de leveduras e fungos) apresentaram maior ganho em peso, peso final e maior concentração de hemoglobina, glóbulos vermelhos e brancos (FIROUZBAKHSH et al., 2011).

Simbióticos são aditivos alimentares formados pela junção de prebióticos e probióticos (Figura 1), visando promover aumento de seus efeitos através da relação sinérgica entre eles (CEREZUELA et al., 2011), como aumento no peso, comprimento, resposta imune (AZEVEDO et al., 2016) e aumento da taxa de crescimento específico, como observado no peixe ornamental ciclídeo Texas (Herichthys cyanoguttatus) durante a fase de larvicultura (MONTAJAMI et al., 2012).

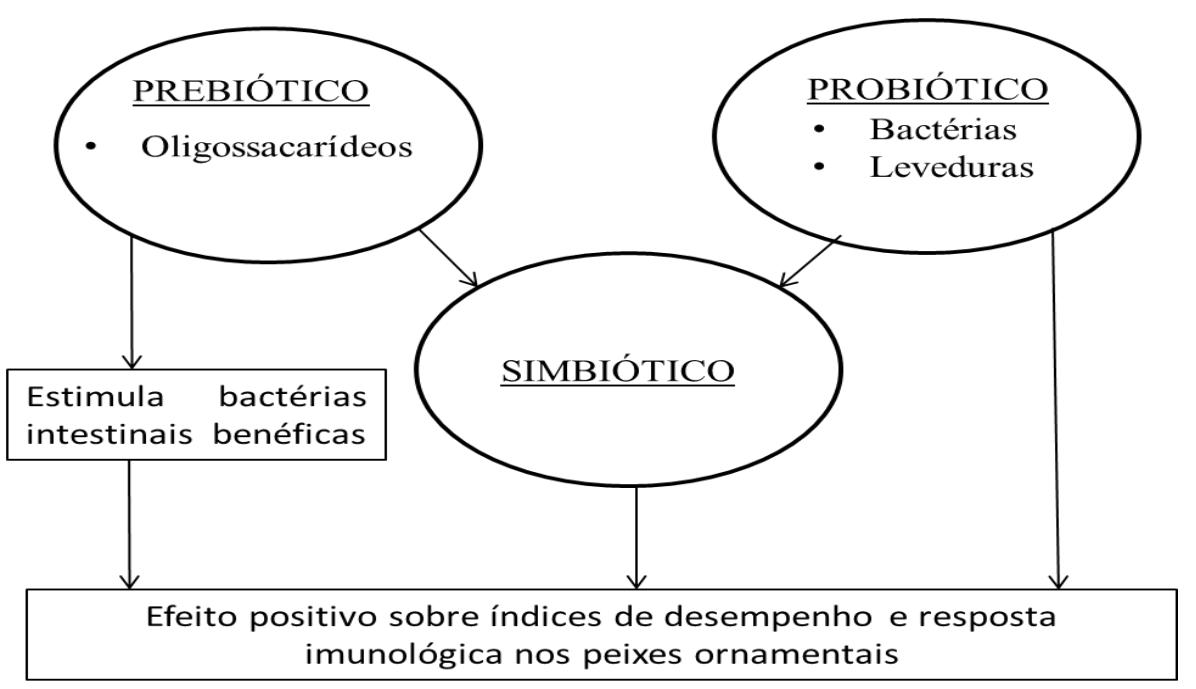

Figura 1 - Efeito dos aditivos prebióticos, probióticos e simbióticos na alimentação de peixes ornamentais (Fonte: Arquivo pessoal). 
Azevedo et al. (2016), ao avaliarem a influência da adição de prebiótico (mananoligossacarídeo - $2 \mathrm{~g} / \mathrm{kg}$ ), probiótico (Bacillus subtilis - $2 \mathrm{~g} / \mathrm{kg}$ e simbiótico (mananoligossacarídeo $-2 \mathrm{~g} / \mathrm{kg}+B$. subtilis $-2 \mathrm{~g} / \mathrm{kg}$ ) em rações para larvas tricogáster (Trichogaster leeri) durante o período de transição alimentar, observaram que houve aumento do peso, comprimento, taxa de crescimento específico e taxa de desenvolvimento específico nas larvas que consumiram a ração com simbiótico.

Maiores taxas de crescimento e desenvolvimento específicos podem implicar em diminuição do tempo de cultivo e, consequentemente, retorno mais rápido do capital investido na piscicultura ornamental (GOMES et al., 2017).

A adição de prebiótico e simbiótico na dieta de larvas tricogáster contribuíram para redução da taxa de mortalidade. Este efeito foi atribuído principalmente a eficiência dos aditivos em aumentar a resposta imune dos peixes (AZEVEDO et al., 2016). Porém, pesquisas relacionadas à inclusão de aditivos alimentares nas dietas para peixes ornamentais são escassas, principalmente, em um segmento onde a variedade de espécies é uma característica marcante.

\section{CONSIDERAÇÕES FINAIS}

Aditivos alimentares têm demonstrado resultados desejáveis para piscicultura ornamental ao melhorar o desempenho de bettas e guppys (enzimas exógenas); aumentar a resposta imune no acará-bandeira (prebiótico) e peixe oscar (probiótico); e intenficar a coloração de carpas coloridas, tricogáster e kinguios pela adição de substancias pigmentantes.

Devido à diversidade de espécies ornamentais brasileiras e sua importancia econômica, recomenda-se que pesquisas sejam realizadas visando definir protocolos de utilização para aditivos alimentares, ampliando os conhecimentos na área e contribuindo para o fortalecimento do setor. 


\section{REFERÊNCIAS}

ABASALI, H.; MOHAMAD, S. Dietary prebiotic immunogen supplementation in reproductive performance of platy (Xiphophorus maculatus). Veterinary Research (Pakistan), v. 4, n. 3, p. 66-70, 2011.

AZEVEDO, R. V.; FOSSE FILHO, J. C.; PEREIRA, S. L.; ANDRADE, D. R.; VIDAL JÚNIOR, M. V. Prebiótico, probiótico e simbiótico para larvas de Trichogaster leeri (Bleeker, 1852, Perciformes, Osphronemidae). Arquivos Brasileiros de Medicina Veterinária e Zootecnia, v. 68, n.3, p. 795 - 804, 2016.

CAMPESTRINI, E.; SILVA, V. T. M. da; APPELT, M. D. Utilização de enzimas na alimentação animal. Revista Eletrônica Nutritime, v. 2, n. 6, p. 259-272, 2005.

COPPOLA, M. M.; TURNES, C.G. Efeito de probiótico na resposta imune. Ciência Rural, v. 34, n. 4, p. 1297-1303, 2004.

DAS, A. P.; BISWAS, S. P. The effect of ripe papaya, Carica papaya, as natural carotenoids meal on body pigmentation and growth performance in banded gourami, Trichogaster fasciata. International Journal of Aquatic Biology, v. 8, n. 2, p 83 90, 2020.

DIAS, J. A. R., ABE, H. A., SOUSA, N. C., SILVA, R. D. F., CORDEIRO, C. A. M., GOMES, G. F. E., ... \& MARIA, A. N. Enterococcus faecium as potential probiotic for ornamental neotropical cichlid fish, Pterophyllum scalare (Schultze, 1823). Aquaculture International, v. 27, n. 2, p. 463-474, 2019.

DIONIZIO, M. A.; BERTECHINI, A. G.; KATO, R. K.; TEIXEIRA, A. S. Prebióticos como promotores de crescimento para frangos de corte - desempenho e rendimento de carcaça. Ciência Agrotécnica, Edição Especial, p. 1580-1587, 2002.

DORCE, L. S.; MENDONÇA, W. C. B.; SIQUEIRA, M. S.; SANTOS, R. F. B.; SOUSA, R. M.; ZIEMNICZAK, H. M.; HONORATO, C. A. Atividade das enzimas digestivas frente a restrição alimentar de peixes ornamentais. Agrarian, v. 13, n. 47, p. 107-113, 2020. 
FERREIRA, A. H. C.; BRITO, J. M.; LOPES, J. B.; SANTANA JÚNIOR, H. A.; BATISTA, J. M. M.; SILVA, B. R.; SOUZA, E. M.; AMORIM, I. L. S. Probiótico na alimentação de pós-larvas de tilápias-do-nilo submetidas a desafio sanitário. Revista Brasileira Saúde Produção Animal, Salvador, v. 16, n. 2, p. 430-439, 2015.

FIROUZBAKHSH, F.; NOORI, F.; KHALESI, M. K.; JANI-KHALILI, K. Effects of a probiotic, protexin, on the growth performance and hematological parameters in the Oscar (Astronotus ocellatus) fingerlings. Fish Physiology and Biochemistry, v. 37, n. 4, p. 833-842, 2011.

FORSATKAR, M. N.; NEMATOLLAHI, M. A.; RAFIEE, G.; FARAHMAND, H.; \& MARTíNEZ-RODRíGUEZ, G. Effects of prebiotic mannan oligosaccharide on the growth, survival, and anxiety-like behaviors of zebrafish (Danio rerio). Journal of Applied Aquaculture, v. 29, n. 2, p. 183-196, 2017.

fRIES, E. M.; BitTARello, A. C.; ZAMINHAN, M.; SIGNOR, A.; FEIDEN, A.; BOSCOLO, W. R. Urucum em dietas para alevinos de kinguios Carassius auratus: desempenho produtivo e pigmentação da pele. Semina: Ciências Agrárias, v. 35, n. 6, p. 3401-3414, 2014.

GOMES, V. D. S., SILVA, J. H. V., CAVALCANTI, C. R., DA FONSECA, S. B., JORDÃO FILHO, J., SILVA NETO, M. R., DA SILVA, F. B. Utilização de enzimas exógenas na nutrição de peixes - revisão de literatura. Arquivos de Ciências Veterinárias e Zoologia da UNIPAR, v. 19, n. 4, p. 259-264, 2016.

GOMES, V. D. S.; AMÂNCIO, A. L. L.; CAVALCANTI, C. R.; BATISTA, J. M. M. Análise das características corporais do peixe Betta splendens. Visão Acadêmica, v. 20 , n. 3, p. $29-38,2019$.

GOMES, V. D. S.; AMÂNCIO, A. L. L.; JORDÃO FILHO, J.; CAVALCANTI, C. R.; BATISTA, J. M. M.; SILVA, J. H. V. Índices de desenvolvimento em juvenis Betta splendens alimentados com aditivos enzimáticos. Visão Acadêmica, v.19, n.4, p. 46 $-65,2018$. 
GOMES, V. D. S.; SILVA, J. H. V.; CAVALCANTI, C. R.; LIMA, M. C.; JORDÃO FILHO, J.; AMÂNCIO, A. L. L. Enzimas exógenas na alimentação do peixe guppy (Poecilia reticulata). Archives of Veterinary Science. v.22, n.3, p.24-29, 2017.

GOUVEIA, L.; REMA, P. Effect of microalgal biomass concentration and temperature on ornamental goldfish (Carassius auratus) skin pigmentation. Aquaculture Nutrition, v. 11, n. 1, p. 19-23, 2005.

JORJANI, M.; ROHANI, M. S.; ROSTAMI, A. M.; AKO, H.; HWAI, R. T. S. Pigmentation and growth performance in the blue gourami, Trichogaster trichopterus, fed Marigold, Calendula officinalis, powder, a natural carotenoid source. Journal of the World Aquaculture Society, v. 50, n. 4, p. 789-799, 2019.

MARYYUM KHALIL, M.; AZMAT, H.; KHAN, N.; JAVID, A.; HUSSAIN, A.; HUSSAIN, S. N.; ULLAH, A.; ABBAS, S. Growth Responses of Striped Catfish Pangasianodon hypophthalmus (Sauvage, 1878) to Exogenous Enzyme Added Feed. Pakistan Journal of Zoology, v. 50, n. 2, p. $685-693,2018$.

MONTAJAMI, S., HAJIAHMADYAN, M., FOROUHAR VAJARGAH, M., HOSSEINI ZARANDEH, A. S., SHIROOD MIRZAIE, F., \& HOSSEINI, S. A. Effect of symbiotic (Biomin imbo) on growth performance and survival rate of Texas cichlid (Herichthys cyanoguttatus) larvae. Global Veterinaria, v. 9, n. 3, p. 358-61, 2012.

MUKHERJEE, A.; MANDAL, B.; BANERJEE, S. Turmeric as a carotenoid source on pigmentation and growth of fantail guppy, Poecilia reticulate. Proceedings of the Zoological Society, v.62, n.2, p.119-123, 2009.

NELSON, D. L.; COX, M. M. Princípios de bioquímica de Lehninger. Porto Alegre: Artmed, 1328 p., 2014.

SAKOMURA, N.K. ; SILVA, J. H. V. ; COSTA, F. G. P. ; FERNANDES, J. B. K. ; HAUSCHILD, L. Nutrição de Não Ruminantes. 1. ed. Jaboticabal: Funep, 678p. 2014. 
SHI, X., LUO, Z., CHEN, F., HUANG, C., ZHU, X. M., LIU, X. Effects of dietary cellulase addition on growth performance, nutrient digestibility and digestive enzyme activities of juvenile crucian carp, Carassius auratus . Aquaculture Nutrition, v. 23, n. 3, p. 618-628. 2017.

SUN, X.; CHANG, Y.; YE, Y.; MA, Z.; LIANG, Y.; LI, T.; JIANG, N.; XING, W.; LUO, $\mathrm{L}$. The effect of dietary pigments on the coloration of Japanese ornamental carp (koi, Cyprinus carpio L.). Aquaculture, v. 342, p. 62-68, 2012.

VASANTHAKUMARAN, M.; BASU, S. B. S.; DEEKSHANYA, K.; RAJA, S. Feed formulation with animal waste as supplements for ornamental fishes Poecilia sphenops. International Journal of Recent Scientific Research, v. 11, n. 7, p. 39263 - 39266, 2020.

ZUANON, J. A. S., SALARO, A. L., \& FURUYA, W. M. Produção e nutrição de peixes ornamentais. Revista Brasileira de Zootecnia, v. 40, p. 165-174, 2011. 